\title{
The Dilemmas of Complexity in Design Studios and The Teachers' Role
}

\author{
Dania Abdelaziz (1) \\ PhD student, Izmir Institute of Technology, Izmir, Turkey
}

Received: March 27th 2021, Revised: April 26st 2021, Accepted: May 12th 2021.

Refer: Abdelaziz, D., (2021), The Dilemmas of Complexity in Design Studios and The Teachers' Role, Journal of Design Studio, V.3, N.1, pp 83-95,

D. Abdelaziz ORCID: 0000-0001-9713-3982,

DOI: 10.46474/jds.904192 https://doi.org/10.46474/jds.904192

\begin{abstract}
Learning in design studios is a complex process that overwhelms the students and results in common mutual-misunderstandings between student-teacher. This research aims to tackle teachers' role in the design studio and explore how they can help students navigate the design learning complexities. The emphasis in learning design is primarily on students who are not aware of their learning. This puts teachers at a disadvantage, sometimes not knowing what to do or concentrating on students' learning but not knowing their teaching, or even focusing on their teaching but not aware of the importance of learning how to teach. What is the teacher-student interaction patterns that can help students get over/deal with complexities in design studios learning environments? Can building up awareness of the teachers' role help the students learn and enhance their teaching methods? The research carried out a literature review to draw a holistic understanding of the dimensions of complexities in design studios and teachers' role to solve these difficulties. It can be concluded the importance of the teacher's role in teaching design is as essential as the role of the students in learning design. Teacher-student interaction enhances the students' design learning and the teachers' design teaching. Students should be aware of their roles as learners and the role of their teachers. Agreeing with the students makes the teachinglearning journey more fruitful while students get rid of their uncertainty and be more confident.
\end{abstract}

Keywords: Design learning, Architectural education, Interaction, Teaching capacities, Educator's role

\section{Introduction}

As a learning culture and design activity, the design studio's role is dominant in various educational programs in architectural departments, see Figure (1). It is an active environment; where students interact intellectually and socially in multiple activities such as; modelling, presenting and drawing. Students analyze and synthesize their ideas (Dutton, 1987). As a result of vague purposes and implicit theories, the learning environment in design studios could be complex (Schön, 1981). This ambiguity leads to common mutual-misunderstandings between studentteacher in design studios. The ambiguity lies in the discrepancies between implicit and explicit messages which confuse students.

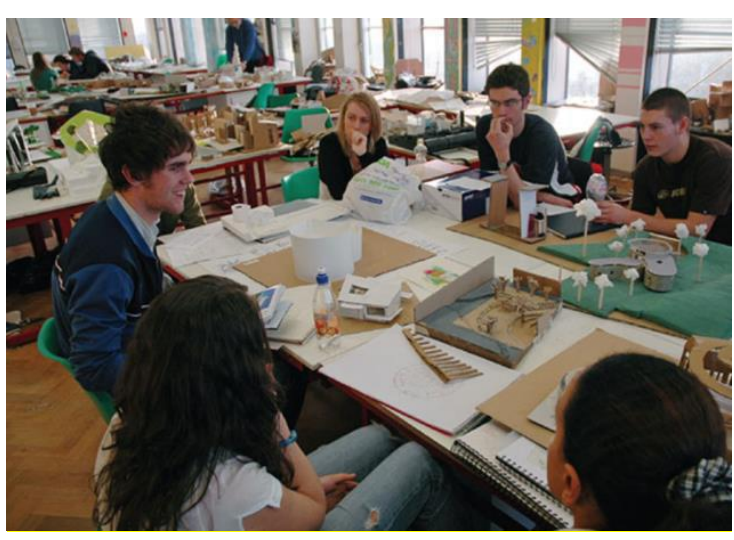

Figure 1: Studio as a learning environment. Source: (Lawson, 2018). 


\section{Journal of \\ Design Studio}

v:3 n:1 July 2021

Many researchers examined the epistemology of design and social relations (student-teacher) in design studios activities in an attempt to enhance the educational outcomes (Dutton, 1987; Schön, 1983; Lawson, 2018; Kolb, 2014). Ledewitz (1985) argues that this requires teachers to deal with design teaching as a design process by itself; thus, they can understand the successful means to deliver the implicit messages to students. To get over this problem; teachers should first agree on the nature of architecture and design (Beinart, 1981) and discuss it with students (Schön, 1981). Design problems are multidimensional; Archer (1979) described them as ill-defined problems while Simon (1973) articulated their ill-structured nature and Rittel \& Webber (1973) stated that they are and wicked problems, see Figure (2). Design problems generally increase their complexities when moving forward to the nest design stage. Schön (1983) emphasized that students can learn design by practising it and think like architects. Design solutions should be creative to solve the complex and multidimensional architectural problems. Cross (1982) stated that students should act and think in designerly ways. The design project reflects the real-world architectural project which has changed from simple to more complex projects. Students in design studios have to deal with the complexity of architectural projects. The increasing complexity of the architectural projects and their design processes require students to use a new design process and methodologies. Highlighting design studios' uniqueness; teaching design cannot rely on one method (Ledewitz, 1985). From this point rises the need to enrich the students' learning experiences; teachers should restructure their
PROBLEM TYPE

WELL-DEFINED PROBLEMS

WICKED PROBLEMS

\section{CHARACTERISTICS}

Goals known

Constraints known

Solutions known

Success criteria known

Optimal solution

\section{ILL-STRUCTURED PROBLEMS}

ILL-DEFINED PROBLEMS

Problem?

Solution?

Success Criteria?

Multiple solutions

No definitive problem

There are many clients and decision makers

A need of an orientation to look for relevant information

$$
\begin{aligned}
& \text { Incomplete, no formula } \\
& \text { Contradictory } \\
& \text { Changing Definition } \\
& \text { No stop rule } \\
& \text { Unique, no cases } \\
& \text { Solution }>>\text { a new problem } \\
& \text { Unknown/No optimal solutions }
\end{aligned}
$$

\section{SOLUTIONS}

The solution can be optimized

\author{
Solutions cannot be \\ optimized but can be \\ satisfactory
}

No definitive solution The consequences of a solution are hardly predictable

Solutions can be at most actionable

Figure 2: Well defined, Ill-defined and wicked problems. Source: (Raami, 2019). 


\section{Journal of \\ Design Studio}

v:3 n:1 July 2021

cognitive schemes; practice teaching as a design process and develop new design models.

\section{Problem Statement}

Learning is a process that merges personal and environmental experiences. It influences to acquire, enrich, or modify students' knowledge, skills, values, attitudes and behaviour. Learning in design studios is a complex process. At the heart of this process, lies the design project. The dimensions of complexity in design learning are; 1) ambiguity (vague purposes, implicit theories, and inherent conditions of inexpressibility) (Schön, 1981, 1983; Lawson 2018; Lawson \& Dorst, 2013), 2) the complexity of design problem (overwhelming in scope and variables) (Archer, 1979; Simon, 1973; Rittel \& Webber, 1973; Lawson, 2006), 3) design development and design moves (Lawson, 2018), 4) Design as a body of knowledge (tacit and explicit) and 5) learning environment (studio environment as a society and the hierarchy of relations) (Dutton, 1991; Savery, \& Duffy, 1995). All this leads to overwhelm the students and also result in common mutual-misunderstandings between student-teacher in design studios.

This study aims to tackle teachers' role in the design studio and explore how they can help students navigate the design learning complexities. Schön (1985) pointed out that learning about design and learning to design is gained by students. Therefore, the emphasis in learning design is mostly on students who are not aware of their learning. This puts teachers at a disadvantage sometimes not knowing what to do or concentrating on students' learning but not knowing their teaching, or even focusing on their teaching but not aware of the importance of learning how to teach. The teacher's role in teaching design is not less important than the students' role in learning design. Teachers have a unique role in building students' knowledge. Teacher-student interaction may enhance the students' design learning and the teachers' design teaching. What are the teacher-student interaction patterns that can help students get over/deal with complexities in design studios learning environments? Can building up awareness of the teachers' role help the students learn and enhance the teachers' ways of teaching? Can a new design learning experience solve these complexities or at least solve some of them (for example, restructuring the hierarchy system in design studio)?

This research believes that there is a necessary need now more than any other time to reshape the teacher-student interaction pattern. This research also aims to identify and examine teachers' essential skills to enhance the learning process by shedding new light on learning complexities. The research assumes that if the teachers were introduced to design teaching/learning theories and styles before practising teaching, it would enrich the students learning outcomes, and help them deal/overcome design learning complexities in design studios. The research carried out a literature review to draw a holistic understanding of the dimensions of complexities in design studios and teachers' role to solve these difficulties. The research started with a general description of the design studio's experience as a learning environment to construct a holistic picture of the situation. They were then followed by a discussion that focused on the complexities of design studios' to link it with the teachers' role that was reviewed in the next section to figure out how teachers can help get over each of them.

\section{The Dimensions of Complexity}

As a learning theory, constructivism hypothesizes that students are not passive recipients of information (knowledgeacquisition). Constructivism describes that they actively construct their knowledge. Learning as a process takes place in interaction with the environment and through the reorganization of their mental structures (knowledgeconstruction metaphor). This interaction happens in three forms (Moore, 1989); LearnerContent Interaction or what it is called "internal didactic conversation" (Holmberg, 1986), Learner-Instructor and Learner-Learner Interaction. This research focuses on the Learner-Instructor approach as one of the different versions of constructivism. The teacher is not a knowledge transmitter. The conduit metaphor (Reddy, 1979), teacher- 


\section{Journal of \\ Design Studio}

v:3 n:1 July 2021

student communication depends on a clear explanation of information being transferred from the teachers to the students' as a vessel. This concept should be avoided; the teacher, on the other hand, is a cognitive guide of learner's learning. In desk crits, the teacher allows students to refine their designs by pointing out the misexpressed elements and suggesting a group of modifications (Critical reflection). Students respond differently, some of them understand while others just imitate what the teacher has told them to do. At the same time, teachers act differently; some tend to impose their ideas on students, other theorize while others leave some elasticity. Figure (3) below shows the desk crits in teacher-centred approach where teachers are the only source of authority and knowledge. On the other hand, collaborative process requires the engagement of students to design a unified design process rather than each member work alone. This shift the student's role from a passive receiver into an active participant, help: 1) shaping their personalities, 2) evolve their ideas by discussing them with their peers in the same group as shown in Figure (6).

Being involved in design projects is how students develop and obtain their knowledge. The process of acquiring knowledge increases in its complexities as they progress to university. First-year and second-year students get involved with design projects without been asked to solve complex structural problems within their project, as the senior students have to do. Even senior students have to write down their design project program. They have many flexibilities; in selecting the site, for instance, or selecting design projects from the many options that the teacher provides them. This flexibility adds pressure on them too. The last year students' task is more complicated; they had to write their own design problem and go through the journey based on their selection. The complexity here has been developed; from finding their path in solving the design problem

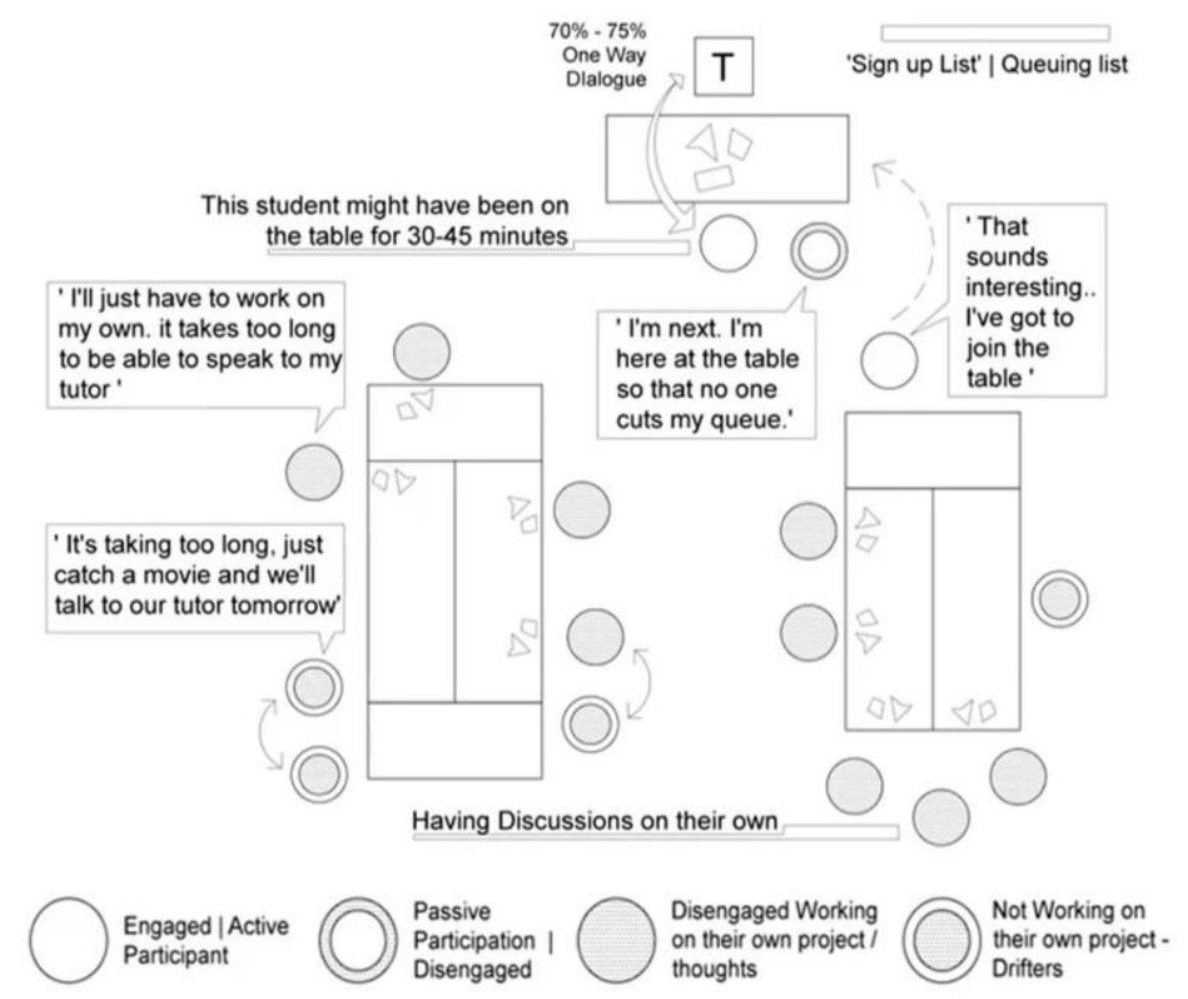

Figure 3: Desk crits in teacher-centred approach where teachers are the only source of authority and knowledge. Source: (Liow, 2020). 


\section{Journal of \\ Design Studio \\ v:3 n:1 July 2021}

to compose a well-defined design problem first, and then solve it. Focusing on last year design students, the teachers' role here is very critical. Students are generally eager to impress teachers by combining many design problems, thinking that they should develop a very complicated design problem that no one has created before. Students here are stuck to a vast program and areas and enormous sites that they could not deal. This leaves no time to deal with other problems they had to solve like structural issues, site circulation, or even succeed in producing well architectural drawings. The different dimensions of complexities in design studios could be grouped as follows;

\subsection{The ambiguity}

It can be agreed that the first year of learning architecture in a design studio is the most challenging. The students do not know "what/why/how" the teacher wants them to do. At the same time, the teacher asks them to start designing. How should we start? Is there a perfect way to do this? What if our proposal was wrong? They find themselves in charge of learning; they begin to dig their own path in learning successfully. Lawson (2018) states that students should take their own creative approach to problems from the onset of design learning. Each student produces his/her own set of solutions, Figure (4). Schön (1983) in this regard states "You should begin with a discipline, even if it is arbitrary... you can always break it open later". But it is not that easy for all students, and it varies depending on their own qualifications, characteristics and how much they are eager to learn. Dorst (in Lawson \& Dorst, 2013) gave an example of one of his students who got exasperated by this during a project and came to his tutor saying "I am an engineering student. I have a right to know what the problem is". Students start designing without even being taught how to design; they start from a vague point, but cannot learn until they start (Schön, 1983). Referring to reflective learning, students must be in the middle of the design process to construct their knowledge. The problem here is more critical to first-year students introduced to new terms at the basic design course, such as been asked to express these architectural terms in 2D \& 3D compositions. Students always wonder how these exercises could be linked to architecture

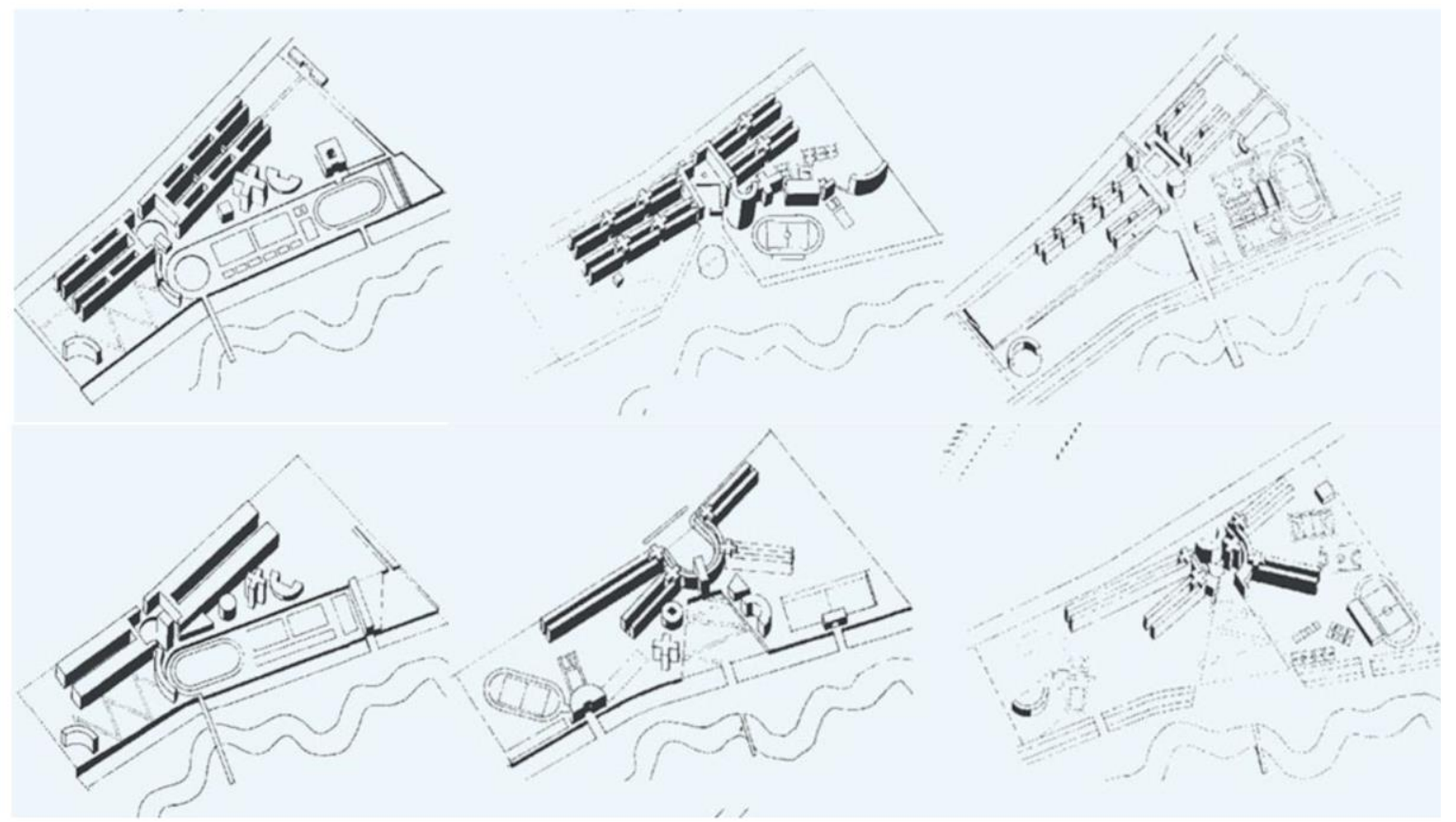

Figure 4: Abstracted 3D alternatives for the same scheme. Source: (Lawson, 2018). 


\section{Journal of \\ Design Studio}

v:3 n:1 July 2021

wondering; aren't we supposed to learn how to build a building?

Nigel Cross (as cited in Lawson, 2018) stated that "what you need to know to design depends upon your approach to designing". There are no boundaries around the knowledge they must depend on when designing, and sometimes there is a lack of theories (Lawson, 2018). Students initiate their own set of questions and dive in the vast sources and disciplines of knowledge to get their creative solution. At some point they find themselves trapped, moving round and round at a point they put themselves at and lost the way to move on.

\subsection{The complexity of the design problem}

Design problems are multidimensional and generally grow more complex through design and while progressing in the school. Lawson (2006) articulates that design problem has no correct solution, and the design process is unending. In other words, the design problem has unpredictable and unknown solutions, and it has nothing with gaining and applying theories directly to solve the problems. If the students are given a problem to solve in a math or a physics class, they know if they used the theories and their body of knowledge, they would come up with one single right answer that agreed with their classmates and teacher. They may choose different approaches though the result is agreed on in advance. But design problems reflect real-life problems that have many aspects that may seem complex to address and solve. The design project is more like a virtual reality version of an architectural project (Chen and Heylighen, 2006). Thus, design problems have a complex structure involving building functions and areas, functional requirements, built environment and site context (urban, cultural, social, environmental, and historical), structural systems, construction methods and other emerging issues associated with the design like sustainability, technological developments, and virtual world as well as different other components.

\subsection{Design development and design moves}

As they go through the design process, students in design projects have to create solutions, find problems, express their ideas in sketches, drawings or even models and then improve them, see Figure (5) (Lawson, 2018). While

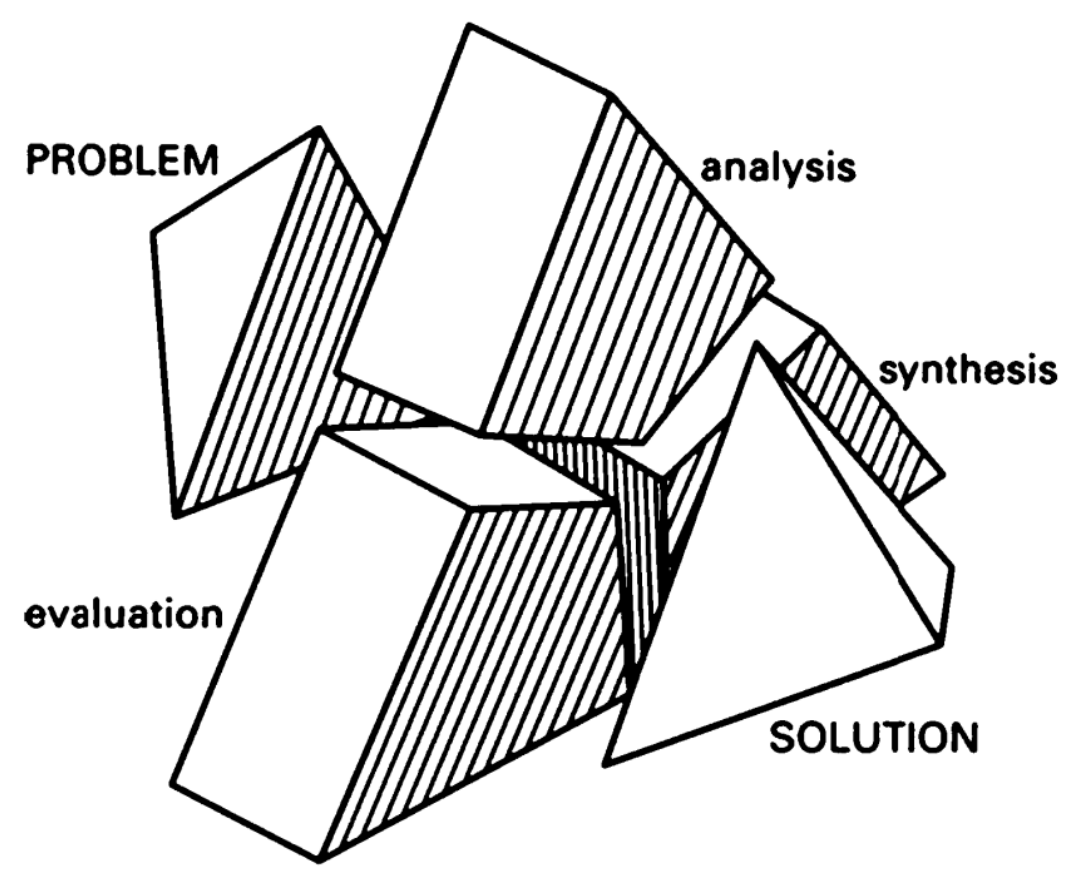

Figure 5: Design process as a negotiation between problem and solution, it is not a one-way approach. Source: (Lawson, 2018). 


\section{Journal of \\ Design Studio}

v:3 n:1 July 2021

students produce creative solutions to the different design problems, they need to deal with uncertainty and decision-making based on limited information and resolve ill-defined "wicked" problems. They need to adopt solution-focused strategies, apply productive/creative thinking, and use visual or spatial media. Lawson (2018) states that designing involves finding problems as much as solving them. The cognitive conflict trigger for learning and the organization and meaning of what is learned is decided. The student should be aware of the purpose of engaging in such an educational environment, which will make them understand what context information they should develop and where, at the end of the course, they applied this knowledge (Savery, \& Duffy, 1995). In teacher-student dialogues, the teacher may draw some lines and sketches to the student to illustrate his words. This dialogue includes words, metaphors, sketches, real-life examples, and constructing or deconstructing models. The teacher here does not draw a full story; s/he just gives hints as glimpses to the students. Sometimes the teacher cannot read the idea behind the students' drawings and understands them wrong. Some students could understand the main idea behind these suggestions and do them in their way while others stuck to the teachers' sketches that are not fully designed and convert these sketches to a design. Generally, this design fails because the student is imitating the teacher's lines without knowing the aim behind the disposition of a space or mass, for example, and how it relates to the whole design. In some design sections, it is easy to notice the teacher's lines in each design. The teachers are somehow imposing their ideas, and many students take these suggestions into account even if different from what they wanted to do. The reasons vary; some of them find this as the easiest and safest way to pass this journey, while others tend to please the teacher to have a higher mark.

\subsection{Design as a body of knowledge}

Polanyi (2009) pointed out that it is possible to define knowledge as explicit and implicit. Implicit knowledge reflects knowledge based on individuals' experience. In the form of evaluations, behaviours, points of view, commitments, and inspiration, it expresses itself in human behaviour. It is typically challenging to convey implicit knowledge in words explicitly. Sometimes, the only ways to present it are metaphors, sketches, or other communication means that do not require the formal use of language. Many experts are also unable to express what they know and are capable of and how they make their choices and come to conclusions on a realistic basis. In the expression "We know more than we can tell" Polanyi (2009) captures the nature of implicit knowledge, and further clarifies the definition in everyday examples such as the ability to identify faces, ride a bicycle or swim without even the slightest understanding of how these things are done. The bulk of the knowledge taught in school is considered theoretical, academic, and therefore explicit. Some particular forms of teaching, such as the practice (Schön, 1985), help students acquire implicit experiences that can only be held as private information. To provide students with explicit knowledge, teachers have to develop their own implicit teaching knowledge.

\subsection{The learning environment}

Cognition in design studios is distributed, and it does not occur within the student as an individual (Savery, \& Duffy, 1995). Via social negotiation and by determining the feasibility of individual understandings, knowledge develops. Lawson (2018) described the studio as a community of scholars in the sense of collaboration between students themselves and their teachers, see figure (6). The social environment is central to the growth of students' individual understanding and the formation of the body of proposals called knowledge. Collaboration is essential so students can assess their own comprehension and analyze others' understanding. In this way, they may create alternate points of view to enrich and extend their perception of specific issues (Savery, \& Duffy, 1995). Dutton (1991) criticized design studios describing that they are hierarchical in their social structure, resulting in a highly competitive culture rather than what it is supposed to be (collaborative). Students tend to hide ideas, projects, and drawings from each other, thus blocking the collaboration. 


\section{Journal of \\ Design Studio \\ v:3 n:1 July 2021}

Developing a competitive spirit as an educational tool may be traced back to BeauxArts' educational system based on studio exercises organized as a monthly competition. Competition stimulates students to do the best, but sometimes competition ends up as a tool to destroy students' collaboration. All this overwhelms the students and results in common mutual-misunderstandings between studentteacher in design studios. Authentic learning means students should be placed in an environment that fosters them to think, recall what they have learned in school, and maybe connect the knowledge they gain from different courses to be involved in real-life activities. These real-life activities are what the teachers had tried their best to prepare the students. Design studios, or maybe to be more accurate, should emphasize developing activities that present the same type of cognitive challenges. The teacher develops design problems in the couple years of design learning, but then the students are somehow responsible for developing their own design briefs, program and problem.

\section{The Role of the Teacher in Literature}

In design studios, the teacher position is to act as an agent who encourages students to be 'empowered' by encouraging students, thus ending dominance. There are two methods of using power; coercive and constructive. Around the same time, the coercive authority should be used over others (in a constructive manner), not over others (to dominate or marginalize) (Yanar, 1999). Ellsworth (as cited in Yanar, 1999) argues that pedagogy is logically based on the premise that "all-knowing is partial, that

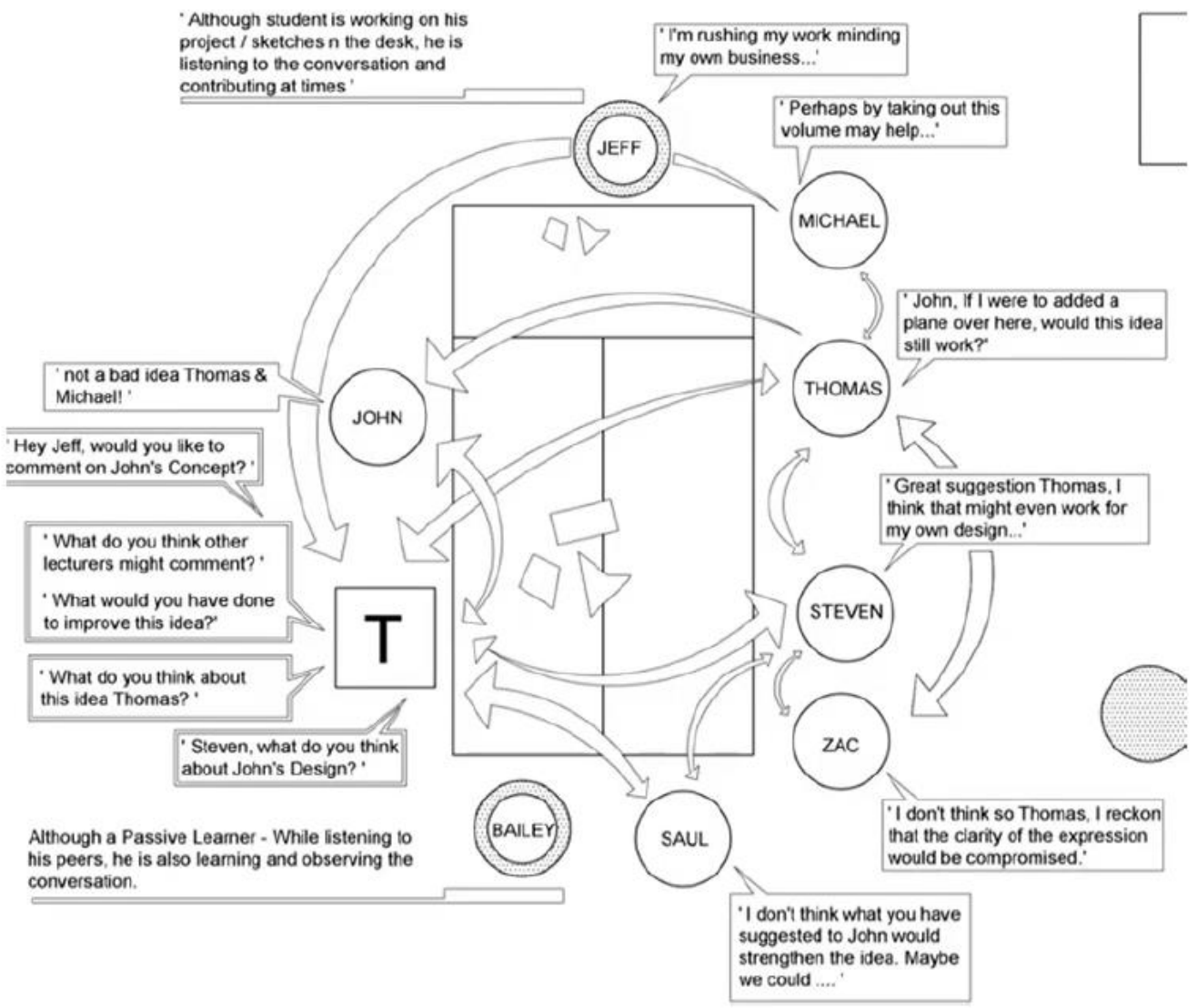

Figure 6: Collaboration in design studio between students themselves and with the tutor. Source: (Liow, 2020). 


\section{Journal of \\ Design Studio \\ v:3 n:1 July 2021}

there are fundamental things each of us cannot know". The design studio has four core elements of pedagogy: the teacher, the student, knowledge and the broader context. In which knowledge development takes place after interaction between teacher and student. Information can be created and replicated between the teacher and the student, who function within the broader sense of developing knowledge, values and identities in cultural and social terms (Yanar, 1999). Lawson and Dorst (2013) identify four core features of an architectural pedagogy: the studio, the design tutorial, the crit, and the library. The education program must have the ultimate goal of motivating and allowing students to become self-sufficient (Lawson, 2018). The teacher's role is to trigger rather than passivate the student. With all his past background, knowledge, beliefs, needs, and desires, the student is invited to the learning-teaching process (Yanar, 1999). There are several roles teachers play. Some tasks may help to accomplish more than others (Lawson, 2018). Some researchers classified the role of teachers as follow;

\subsection{Schön's studio (Yanar, 1999)}

Schön positions the teacher at the forefront of teaching-learning, and s/he marginalizes the student's voice, see Figure (7). The views of Schön are linked to the pedagogical apprenticeship model, which implies certain problems, such as assigning the student a passive role and uncritical adoption of the view of the status quo. The student is "confused" in Schön's design studio much of the time, but Schön sees this as an implicit, normal and essential aspect of studio pedagogy. Schön's distinction between the teacher's positions and the student will cause problems by giving the teacher a superior position and a somewhat opposite one. As discussed on as human beings, we tend to internalize negative expectations. If the Schöns student internalizes all the mentioned expectations, Yanar (1999) challenges the efficacy of Schöns' pedagogical method in educating analytical practitioners who think independently. An impediment to a dialogical relationship is the hierarchical asymmetry between the instructor and the learner. This asymmetry is also an impediment to reflection if the conversation is considered a reflective relationship between two or more individuals.

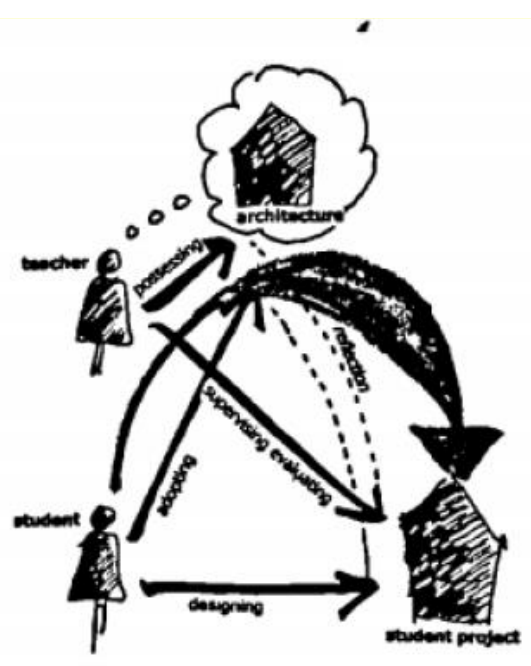

Figure 7: teacher-centred and rigid approach to knowledge construction. Source: (Yanar, 1999).

5.2. McLaren's (1988) classification: McLaren identifies three categories of teachers: a. The 'entertainer': Although the teacher's rich knowledge and experience, his communication skills drive students to rely on him, preventing the intense dialogue with students. Here, the teacher stimulates shallow learning, and students will thus remain unreflective learners. It can easily notice the teacher's influence on the decision making of students' solutions and design.

b. The 'hegemonic overlord': The teacher here aims to impose unique views on the learners. This suggests that not all students will be involved, and they will not be allowed to respond to the teacher's comments.

c. The 'liminal servant': utilizing critically reflective dialogue helps the students build their knowledge. Teaching here is student-centred, enabling students to voice their thoughts, giving them valuable, constructive advice.

\subsection{Lawson's (2018) classification:}

a. The consultant role: The teacher's role here is to help with a design project, emphasizing 


\section{Journal of \\ Design Studio}

v:3 n:1 July 2021

specific and particular design qualities rather than teaching generic issues. Students are not satisfied with their design's current state and want some advice on how to improve it. In this role, the teacher is probably working more like a senior colleague in design practice. The role of part-time studio teachers who spend their time primarily in practice is helpful.

b. The master role: Generally, the teacher here is a practice teacher, and s/he an influential designer. Perhaps the student will be fascinated to get in contact with such a teacher. In such a scenario, the teachers can press their thoughts and sometimes miss what a student tries to accomplish but cannot demonstrate strongly or entirely articulate.

c. The parrot role: Lawson makes an analogy and sees the teacher sitting on the students' shoulder squawking like a parrot to remind him of something important. The teacher's task here is to guide the student in the right direction while knowing what students want to do to make it easier and more fruitful for them to develop solutions. The teacher here appreciates that learners can learn a lot from each other and do so. It focuses on promoting, rather than conducting, discovery and learning.

5.4. Kolb's (2014) classification: Kolb's Educator Role Profile (KERP) theory was developed to help teachers explain the role they prefer to play in helping others learn. Their position involves their philosophy of education, teaching style, set of goals, and adopted methods to encourage learning. The teacher's role is most commonly associated with teaching in the classroom or seminars, as a supervisor, consultant, parent or friend (1) (Kolb et al., 2014).

a. Coach: Works one-on-one with learners to incorporate and improve their ongoing learning while reflecting on their work.

b. Facilitator: Provides motivations, creates personal relationships with students, fosters dialogue and self-knowledge.

c. Elevator: Objective results-oriented style, sets performance goals set and frameworks to measure earning.

d. Expert: Reflective style (authoritative), organizes the subject and provides information with lectures and texts.
By the end of the design course, many teachers passed through most or maybe all the modes. It is somehow hard to see where each task ends and starts with the next. However, the absence of explanation and articulation of teachers' positions can also confuse the student. At the end of a design project, the teachers should ask themselves what happened, their roles, and how any material collection should be treated (Lawson, 2018).

\section{Discussion}

In design studios, the teacher guides, stimulates, and motivates the students in the right way to build their knowledge. By generating responses to design problems, teachers can reflect on the students' work and explain what they are supposed to do. The main aim of feedbacks, desk crits or jury critiques is to develop the students' abilities in design. This can be achieved by the continuous cycle of revisiting design problems in design studios. Teachers ask students to explain their ideas, reason out their arguments/decisions, present their work and attend jury discussions. A variety of internal developmental processes are provoked; students may reconsider a design decision, reflect ideas on their work, rethink how to manipulate an idea, which helps them develop their own cognition. In design studios, desk crits, and jury critiques, foster students constantly reflect on their design projects due to; inner dialogue, peer dialogue, and teacher dialogue. Every week, students are asked to pin up their work and express in words what they have designed, see Figure (8). They learn from each other, how his colleague designed the composition, presented it or expressed it in terms. The teacher's role here is to suggest a new kind of move. In other words, teacherstudent dialogue here may take many forms and may increase complexity. This depends on the teacher's role while sometimes unintentionally shifting roles and switching seamlessly (Lawson, 2018). In these dialogues, the teacher also helps students on how to use terms in the right position. Students pay attention to how the teacher constructs a full architectural sentence. 

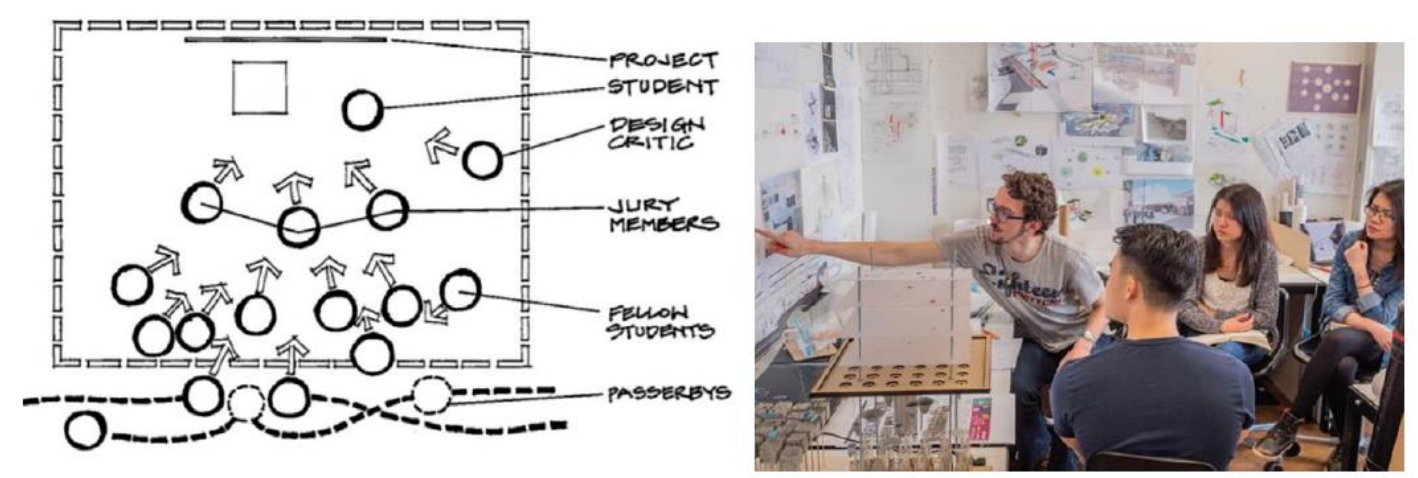

Figure 8: Design Jury Organization. Source: left (Anthony, 1991), right (Lawson, 2018).

Moreover, the teacher allows students to refine their designs and suggesting a group of modifications. As discussed earlier, the teacher must agree on the nature of architecture and design (Beinart, 1981) and discuss it with students (Schön, 1981). Here, it is essential to differentiate between reflective practice (Schön, 1983) and critical reflection (Thompson \& Pascal, 2012). The first is criticized as a teacher-centred approach by Yanar (1999) and described as traditional' reflective practice by Thompson \& Pascal (2012). On the other hand, critical reflection, which was based on reflective practice, is more student-centred. This approach goes beyond limitations and establishes a more firmly and sociologically informed critical reflective practice, providing a basis for emancipatory practice (Thompson \& Pascal, 2012). Rapoport (1984) discussed some difficulties that affect their learning process and understanding in design studio environments. For example, some teachers tend to be subjective depending on their personal aesthetic preferences (likes and dislikes) while giving feedback instead of being based on a theory that limits their educational development. Other design teachers, implicitly and without recognizing, impose their attitudes about design (Ledewitz, 1985) this asymmetrical relation of power affects the educational process negatively (Dutton, 1987). Some students try to satisfy and appease their teacher while sometimes they try to defend their thoughts. Some students cling to essential principles in design that seem to have unbeatable odds. The teacher has to face this situation when students are attached to specific ideas which even creates many difficulties. Another of the essential skills students must acquire is understanding when to let go of these ideas (Lawson, 2018). There are no boundaries around the knowledge students must depend on; students found themselves trapped. At this point, the teacher's role is to lead them to the escape door without giving them the keys; at least now they know their escape path. The teacher may also provide them with confidence by stepping them one step behind or ahead, so they are saved from being in a stuck-up situation. The teacher will act as the light at the end of the tunnel, and students have to fight until they reach this source of light. At least at this point, they are confident of choosing the right path, the right beginning. This will give them the much-needed motivation and energy to fight until the end.

\section{Conclusions}

Design problems as real-life problems have many aspects that may seem complex to address and solve; students need to be creative and skilled. Thus, teachers are responsible for forming new and unique methods and approaches to help students overcome these complexities and help them in mastering new skills and acquire up-to-date knowledge. Teachers should be aware of their role in teaching design and should learn how to teach design. Building teaching capacities, mastering essential teaching skills, and teaching as design by itself would enrich the teaching-learning experience. Teachers need to rethink their 


\section{Journal of \\ Design Studio}

v:3 n:1 July 2021

teaching style, redesign their course syllabus, teaching aims, teaching methods, and desired outcomes. As a first step, they need to discuss with the students and make everything clear for them. Students should be aware of their roles as learners, what they are supposed to do, which skills they need to develop and what they will learn from this course. Building awareness of the teacher's role will help students gain their knowledge with confidence and help them deal with design learning's different complexities.

The social nature of learning distinguishes the learning process in design studios; it is instructional, conversational or rather includes dialogue. If we reflect Vygotsky's idea of the Zone of Proximal Development in design studios; it will help explain the maximization in the students' learning potentials. Vygotsky (1978) argues that students can develop their cognition in two different levels; seeking knowledge at their own (actual developmental level) and while interacting with their peers or teachers (potential developmental level). In design studios, students interact with each other in this social environment; the teacher's behaviour alters their motivation and learning process. To overcome these complexities, teaching in design studios, should be studentcentred. The teacher, with his sufficient knowledge, supports, advises and gives confidence to the students. Teacher-student dialogue builds on students' knowledge. Teachers, as knowledge builders, are not the primary source of knowledge. Teacher-centred teaching marginalizes the student's voice, ends up with shallow learning, and drives students' tendency to mimic the teacher, thus breaking the reflective learning process. Teachers should not Impose or press their views on the student and avoid being result-oriented. Teachers should use different means of delivering knowledge which motivate students, involve all students and facilitates their learning process.

\section{References:}

Anthony, K. H. (1991). Design juries on trial: The renaissance of the design studio. Van Nostrand Reinhold.
Archer, B. (1979). Design as a discipline. Design studies, 1(1), 17-20.

Beinart, J. (1981). Structure of the Content of Design. Architecture and Education Study, 1, 159-338.

Chen, J. D., \& Heylighen, A. (2006). Learning design teaching. Changing Trends in Architectural Design Education, 577-588.

Cross, N. (1982). Designerly ways of knowing. Design studies, 3(4), 221-227.

Dutton, T. A. (1987). Design and studio pedagogy. Journal of architectural education, 41(1), 16-25.

Dutton, T. A. (1991). The hidden curriculum and the design studio: Toward a critical studio pedagogy. Voices in architectural education: Cultural politics and pedagogy, 165-194.

Holmberg, B. 1986. Growth and Structure of Distance Education. London: Croom-Helm.

Kolb, A. Y., Kolb, D. A., Passarelli, A., \& Sharma, G. (2014). On becoming an experiential educator: The educator role profile. Simulation \& Gaming, 45(2), 204-234.

Kolb, D. A. (2014). Experiential learning: Experience as the source of learning and development. FT press.

Lawson, B. (2006). How designers think: The design process demystified. Routledge.

Lawson, B. (2018). The Design Student's Journey: Understanding How Designers Think: Routledge.

Lawson, B., \& Dorst, K. (2013). Design expertise. Routledge.

Ledewitz, S. (1985). Models of design in studio teaching. Journal of architectural education, $38(2), 2-8$. 


\section{Journal of \\ Design Studio \\ v:3 n:1 July 2021}

Liow, Z. (2020). Two minds are better than one: Breeding collaborative mindsets for emerging design-led transdisciplinary practices. Online lecture:

https://www.youtube.com/watch?v=QO8rtA41 JVE\&t=194s. (accessed 15 March 2021)

McLaren, P. L. (1988). The liminal servant and the ritual roots of critical pedagogy. Language Arts, 65(2), 164-180.

Moore, M. G. (1989). Three types of interaction. Polanyi, M. (2009). The tacit dimension. University of Chicago Press.

Raami, A. (2019). Towards solving the impossible problems. Sustainability, Human Well-Being, and the Future of Education, 201.

Rapoport, A. (1984). There is an urgent need to reduce or eliminate the dominance of the studio. Architectural Record, 172(12), 100.

Reddy, M.J. (1979). "The Conduit Metaphor -A case of frame conflict in our language about language". in Metaphor and Thought, Ortony, A. ed. Cambridge University Press, Cambridge, 164-201.

Rittel, H. W., \& Webber, M. M. (1973). Dilemmas in a general theory of planning. Policy Sciences, 4(2), 155-169.

Savery, J. R., \& Duffy, T. M. (1995). Problem based learning: An instructional model and its constructivist framework. Educational technology, 35(5), 31-38.

Schön, D. (1981). Learning a Language, Learning to Design. Architecture Education Study, 1 .

Schön, D. (1983). The reflective practitioner. How Professionals Think In Action. Basic Books, Inc. USA.

Schön, D. (1985). The design studio: An exploration of its traditions and potential. London: Royal Institute of British Architects.
Simon, H. A. (1973). The structure of illstructured problems. Artificial intelligence, 4(34), 181-201.

Thompson, N., \& Pascal, J. (2012). Developing critically reflective practice. Reflective practice, 13(2), 311-325.

Vygotsky, L. (1978). Social development theory. Instructional Design.

Yanar, A. (1999). The silenced complexity of architectural design studio tradition: pedagogy, epistemology and the question of power (Doctoral dissertation, Oxford Brookes University).

Online references:

1. Kolb Educator Role Profile (KERP) https://learningfromexperience.com/themes/kol b-educator-role-profile-erp/ (accessed 15 Jan 2021) 